\title{
Proposal for a new type single quantum flux device by the ferromagnet-superconductor-ferromagnet junction
}

\section{強磁性体一超伝導体一強磁性体接合を利用した新しい単一磁束 量子デバイスの考案}

\author{
Morishige YONEDA \\ Department of Electric Engineering, Nippon Electric College, \\ 1-25-4 Hyakunincyo Shinjyuku-ku Tokyo, 160 JAPAN TEL;81-3-3369-9331 FAX;81-3-3363-7685 \\ Masaaki NIWA and Shozo SHINOHARA \\ Depatment of Materials Science and Engineering, Tokyo Denki University, \\ 2-2 Kanda,Nishikicyo Chiyoda-ku Tokyo, 101 JAPAN TEL;81-3-5280-3403 FAX;81-3-5280-3570 \\ ( Received 18, June 1996 Accepted 29, August 1996 )
}

The single-electron device is a quantum effect device which operates by using the single electron tunneling created by a Coulomb blockade. In this analogy, we propose the single quantum flux device which operates by using the single quantum flux tunneling. The single quantum flux transistor consists of the ferromagnetsupercnductor-ferromagnet junction of the sandwich structure. In this paper, we consider the physical mechanisms that lie behind the single quantum flux tunneling, and advanced a theoretical analysis to control this device

Keywords: Coulomb blockade, single-electron device, ferromagnet-supercnductor-ferromagnet junstion, single quantum flux device, micro-Josephson junction

\section{I . INTRODUCTION}

単一電子デバイスはクーロン・ブロッケイド現 象によって生じる単一電子のトンネリングを利用 することによって機能する量子デバイスである。 この類推として、我々は単一磁束量子のトンネリ ングを利用した単一磁束量子デバイスについて考 案した。この単一磁束量子デバイスはサンド ウィッチ構造である強磁性体一超伝導体一強磁性 体接合(FM-S-FM接合)から構成されている。本論 文に於いて我々は、これらの単一磁束量子デバイ スの背後にある物理的メカニズムついて考察し、 そしてこのデバイスを制御するための理論的条件 を提出する。

最近微細加工技術、低温技術の進歩と共に量子 効果を利用した科学技術が顕在化し、電荷及び電 流を電子 1 個のレベルで制御することが可能と なった。現在、この量子効果を利用した技術の応 用として実用的な面で最も注目を浴びているのが クーロン・ブロッケイド現象 ${ }^{1}$ を動作原理とする一 連の単一電子デバイズであり、代表的なものとし て単一電子メモリ、ターンスタイル、単一電子卜
ランジスター、4単一電子ポンプ等が知られている。 この中で最も基本的な素子である単一電子トラン ジスターは電界効果トランジスタの一種と見なす ことが出来、超高感度、高精度な為、電荷測定器、 標準電流源、サイクルカウンタ等の応用が考えら れ、消費電力の面に於いても非常に大きな利点が あると期待されている。ここで重要なことは、単 一電子デバイスはすべて、ミクロな静電場環境に 於ける単一電子のトンネリングを利用している点 である。一方、微小ジョセフソン接合系の場合、 或条件（接合の抵抗、キャパシタンス、インダク タンス、温度、外部磁場等）のもとでクーパー対 の電荷と磁束量子の役割を入れ替えてもジョセフ ソン効果と類似のタイプの方程式が成立する双対 効果洊在が確かめられている。この条件下では クーパー対の電荷の代わりに磁束量子がトンネリ ングすると考えることが出来る。そこで我々は単 一電子のトンネリングを利用する代わりに磁束量 子のトンネリングを利用した単一磁束デバイスに ついて考案したのでこれについて報告する。 


\section{II . FORMULATION}

\section{A.一般的原理}

クーロン・ブロッケイド現象とは、非常に小さ い静電容量を持つ極微小トンネル接合を十分低温 にした場合、電子 1 個がトンネリングするために 必要なエネルギーの変化分 ${ }^{2}($ 例えば一辺が $0.1 \mu \mathrm{m} \times 0.1 \mu \mathrm{m}$ 程度の微小トンネル接合の場合、静 電容量 $C$ は $10^{-15} \mathrm{~F}$ 程度となり、1 電子帯電エネル ギー $\frac{e^{2}}{2 C}$ は温度に換算すると $1 K$ 程度である。)

$$
\Delta \mathrm{E}=\frac{(Q \pm e)^{2}}{2 C}-\frac{Q^{2}}{2 C}=\frac{e}{C}\left(\frac{e}{2} \pm Q\right),
$$

は、 $\frac{e}{2}>|Q|(Q$ はトンネリングが起こる直前に接合 電極に蓄えられていた実行的な表面電荷)の場合 $\Delta \mathrm{E}>0$ となり、接合の温度をこれより十分下げる ことによって、トンネル確率 $\exp \left(-\Delta \mathrm{E} / k_{B} \mathrm{~T}\right)$ がほと んど0となることをいう。従って、このような微 小トンネル接合に定電流 $I$ を流すとほぼ一定の時 間間隔 $\tau=e / I$ で総電荷 $e$ の電流パルスがトンネル 障壁をトンネルする現象が起こる、このような現 象はSET振動(Single-Electron-Tunneling-Oscillations) ${ }^{2}$ と呼ばれる。

以上のような現象は、2つの微小な超伝導体の 接合から成る微小ジョセフソン接合 ${ }^{2} の$ 場合に関し ても重要である。この場合、系のエネルギーは

$$
\left.\begin{array}{l}
E=E_{c}+E_{J}(1-\cos \theta), \\
E_{c} \equiv \frac{Q^{2}}{2 C}, Q \equiv n 2 e, E_{J} \equiv \frac{\hbar I_{c}}{2 e} .
\end{array}\right\}
$$

によって与えられる。ここで、 $E_{c}$ は静電エネル ギー、 $E_{J}$ はジョセフソン接合エネルギー、Cは接 合のキャパシタンス、 $I_{c}$ は臨界電流、2eはクー パー対の電荷量、 $n$ はクーパー対の数、 $\boldsymbol{\theta}$ は 2 つ の超伝導体電極の秩序パラメータの位相差である。 今、 $(\hbar / 2 e) Q$ をこの系の運動量、 $\theta$ を位置と形式的 に見なせば、式(2) は周期的ボテンシャル $E_{J}(1-\cos \theta)$ の中を運動する質量 $m \equiv(\hbar / 2 e)^{2} C$ をも つ粒子と形式的に解釈出来る。いま、微小なジョ セフソン接合 $E_{J}<<E_{c}$ の場合について量子力学的 に解釈すると、運動エネルギー $Q^{2} / 2 C$ (実際は静電 エネルギー)をもった系が弱い周期的ポテンシャル の影響によりエネルギーバンドを作り、位相差 $\theta$ は任意の值をとることが出来るようになったこと を示している。微小ジョセフンン接合の場合も クーロン・ブロッケイド現象に関しては、本質的 に同じ原理に基づいているが、異なるのは、エネ
ルギーバンドを作っていることと、通常の金属に 対し電荷が $2 e$ を基本単位として量子化されている ため、Cooper対 1 個がトンネリングするための静 電エネルギーの変化分が

$$
\Delta \mathrm{E}_{c}=\frac{(Q \pm 2 e)^{2}}{2 C}-\frac{Q^{2}}{2 C}=\frac{2 e}{C}(e \pm Q),
$$

となることである。この場合、 $e=|Q|$ を境に、 $e>|Q|$ のとさはトンネリングが禁止され、 $e<|Q|$ の ときは $\Delta \mathrm{E}_{c}<0$ となるから、トンネリングが起こり、 Cooper対電流パルスが流れる。ここでも微小トン ネル接合のときと同様に定電流 $I$ を注入すると、 SET振動の場合の 2 倍の時間間隔 $\tau=2 e / I$ で総電荷 $2 e$ の電流パルスがトンネル障壁をトンネルする現 象が起こる。このような現象は周期的ポテンシャ ル中を運動する電子状態との類似性からブロッホ 波振動と呼ばれる。

次に、ジョセフソン効果と双対な効果 ${ }^{6,7}$ が起 こっている系について考える。これのより詳しい 解説はAPPENDIXにまとめておいた。このよう な効果は微小なジョセフソン接合で8起こり、この 効果は位相量子トンネル効果 ${ }^{6}$ (PQT効果) と呼ばれ、 Cooper対の代わりに磁束量子がトンネルする。こ の効果を利用した素子はPQT素子と呼ばれ、その エネルギー9

$$
\begin{aligned}
& E=E_{M}+\frac{e^{2}}{C \pi^{2}}(1-\cos \tilde{\theta}), \\
& E_{M} \equiv \frac{\Phi^{2}}{2 L}, \Phi \equiv \Phi_{0} \tilde{n}, L \equiv \frac{\hbar}{2 e I_{c}}=\frac{\Phi_{0}}{2 \pi I_{c}} .
\end{aligned}
$$

ここで $E_{M}$ は静磁気エネルギー、 $\tilde{n}$ は磁束量子 の数、 $L$ は超伝導部分のインダクタンス、 $\tilde{\theta}$ は 2 つの非超伝導体電極間の非超伝導秩序パラメータ (渦糸密度に関する秩序を表す秩序パラメータ)の 位相差である。(4)式の定義から、 $L$ は超伝導部分 の臨界電流 $I_{c}$ に反比例しているから、使用する超 伝導材料の性質によって決められる定数 ${ }^{9}$ である。 ここでも、微小ジョセフソン接合の場合と同様、 形式的に $E_{M}$ を運動エネルギ一項と見なせば、(4) は周期的ポテンシャル $\frac{e^{2}}{C \pi^{2}}(1-\cos \tilde{\theta})$ のを運動す る粒子のエネルギーと解釈出来る。ここでも $e^{2} / C \pi^{2}<<E_{M}$ が成立する領域について量子力学 的に解釈を施すと、微小なジョセフソン接合の場 合のブロッホ波振動と類似な現象が考えることが 出来る。Figure.1は横軸に磁束、縦軸にエネルギー をとったときのエネルギーバンドを示している。 


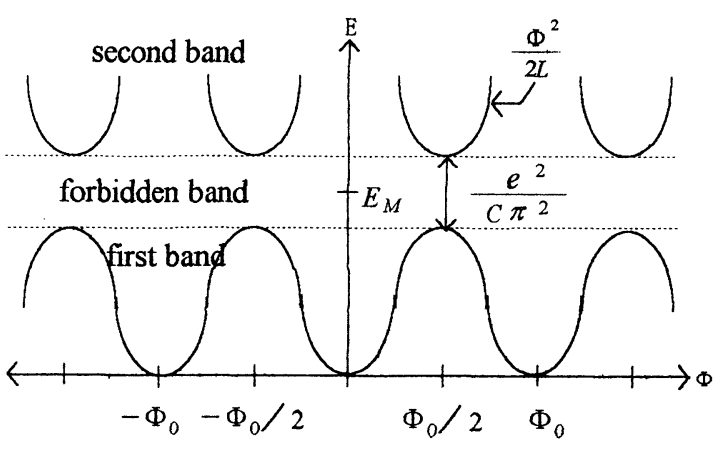

FIG.1. The energy band to the duality system of Josephson junction

磁束量子 1 個がトンネリングしたときの静磁気 エネルギーの変化分は

$$
\Delta \mathrm{E}_{M}=\frac{\left(\Phi \pm \Phi_{0}\right)^{2}}{2 L}-\frac{\Phi^{2}}{2 L}=\frac{\Phi_{0}}{L}\left(\frac{\Phi_{0}}{2} \pm \Phi\right) .
$$

となる。この場合、 $\Phi_{0}=|\Phi|$ を境に、 $\Phi_{0}>|\Phi|$ のと きは磁束量子のトンネリングが禁止され、 $\Phi_{0}<|\Phi|$ のさは $\Delta \mathrm{E}_{M}<0$ となって、磁束量子の卜 ンネリングが起こり、接合部の磁束に時間的変化 が生じ、パルス状の電位差が発生する。ここでは、 微小トンネル接合や、微小ジョセフソン接合の場 合のように定電流 $I$ ではなく、定電圧 $V$ を接合部 に加えると時閒 $\tau=\Phi_{0} / V$ 間隔で総磁束 $\Phi_{0}$ のパルス 電圧がトンネル障壁に発生する現象が起こると予 想出来る。我々は、(4)式以下に示したような単一 磁束量子トンネル接合の具体的モデルとしてFig.2 のようなを強磁性金属で超伝導体をサンドウィチ 状に挟んだ接合(FM-S-FM接合)を超伝導細線に よって接続した回路を考えた。

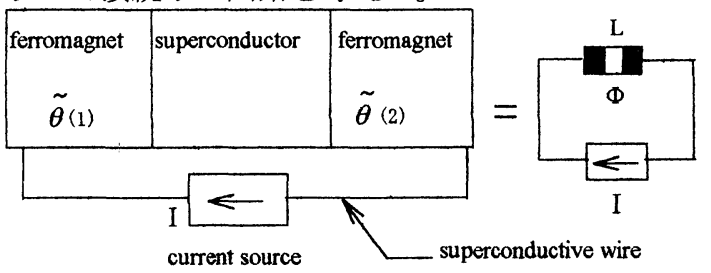

FIG.2 Schematic of superconductor-ferromagnetsuperconductor junction and its equivalent circuit

$\tilde{\theta}(1) 、 \tilde{\theta}(2)$ はそれぞれ左側、右側の強磁性金属 に於ける非超伝導秩序パラメータ(渦䒺密度の秩序 パラメータ)の位相、Lは接合のインダクタンス、 Фは接合の抱える全磁束数を表している。いま、 FM-S-FM接合での磁束量子トンネリングに関する ミクロな意味での解釈について考えてみる。強磁 性状態注超伝導状態と同様にマク口な量子効果と して知られていて、極低温に於ける強磁性状態の
スピン摇らぎはスピン波という形で伝播する。こ れは量子論的にはマグノンというBose粒子的な素 励起として取り扱うことが出来る。マグノンが Bose凝縮を起こすとスピンの向きが巨視的に揃つ たコヒーレント状態が出現する。従って、FM-SFM接合における磁束量子のトンネリングを超伝導 秩序の立場でなく、強磁性秩序の立場で考えた場 合、一方の強磁性層から超伝導障壁を介して、他 方の強磁性層へのマグノンがトンネルしたと解釈

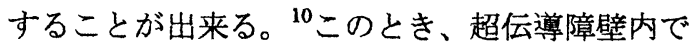
は磁束量子 $\Phi_{0}=h / 2 e$ の整数倍でしか磁束の侵入を 許さないという制限があるためトンネリングする マグノン数の摇らぎも抑制されるであろう。我々 はこのような現象をジョセフソン接合に於ける クーロン・ブロッケイドとのアナロジーから磁気 ブロッケイドmagnetic blockadeと名付けた。

\section{B.磁柬量子トランジスターの動作原理}

我々は磁気ブロッケイドの応用として、Fig.3に 示すようにFM-S-FM接合を二つ並列につないだ磁 束量子トランジスターを考案した。

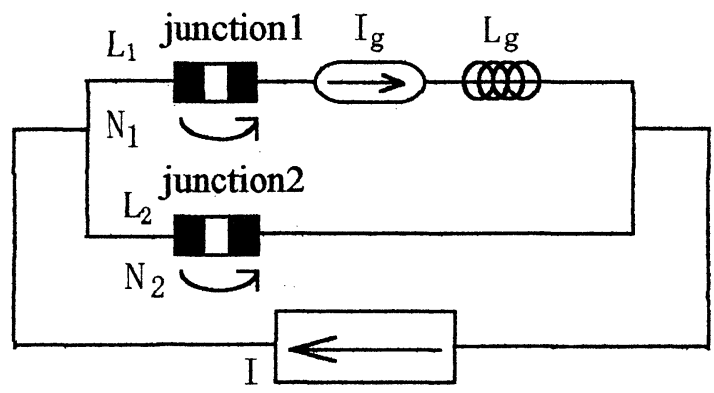

FIG.3 Schematic of quantum magnetic flux transistor

ここで、これらの素子の接続はすべて超伝導細 線によって成されているものとする。 $I_{g}, L_{g}$ はそれ ぞれ接合1に直列に挿入された電流源の電流とイ ンダクタンスを表しているが、その添字 $g$ は単一 電子トランジスターに於けるゲート端子の役割を するため形式的つけた。いま、接合 $1 、$ 接合 2 で、 それぞれ $N_{1} 、 N_{2}$ 個の磁束量子がトンネルした場 合の系の自由エネルギーについて計算すると、

$$
\begin{gathered}
F\left(N_{1}, N_{2}\right)=\frac{1}{2} \frac{\left[\Phi_{0}\left(N_{1}-N_{2}\right)+L_{g} I_{g}\right]^{2}}{L_{\Sigma}} \\
-\Phi_{0} N_{1} \frac{\left(L_{2}+L_{g}\right)}{L_{\Sigma}} I-\Phi_{0} N_{2} \frac{L_{1}}{L_{\Sigma}} I,
\end{gathered}
$$

$L_{\Sigma} \equiv L_{1}+L_{2}+L_{g}, \Phi_{1} \equiv N_{1} \Phi_{0}, \Phi_{2} \equiv N_{2} \Phi_{0}$.

となる。これから接合1で磁束量子 1 つのトンネ リングが禁止される条件を求める。 磁束数の変化 $N_{1} \rightarrow N_{1} \pm 1$ に対して 


$$
\begin{aligned}
\delta F\left(N_{1} \pm 1, N_{2}\right) \equiv & F\left(N_{1} \pm 1, N_{2}\right)-F\left(N_{1}, N_{2}\right) \\
=\frac{1}{2 L_{\Sigma}} & \left\{\Phi_{0}{ }^{2} \pm 2 \Phi_{0}{ }^{2}\left(N_{1}-N_{2}\right) \pm 2 \Phi_{0} L_{g} I_{g}\right\} \\
& \quad-( \pm 1) \frac{\left(L_{2}+L_{g}\right)}{L_{\Sigma}} \Phi_{0} I>0
\end{aligned}
$$

が成り立てば接合1のトンネリングは禁止される。 同様に接合 $2 て ゙$ 磁束のトンネリングが禁止される 条件は

$$
\begin{aligned}
\delta F\left(N_{1}, N_{2} \pm 1\right) \equiv & F\left(N_{1}, N_{2} \pm 1\right)-F\left(N_{1}, N_{2}\right) \\
= & \frac{1}{2 L_{\Sigma}}\left\{\Phi_{0}{ }^{2} \mp 2 \Phi_{0}{ }^{2}\left(N_{1}-N_{2}\right) \mp 2 \Phi_{0} L_{g} I_{g}\right\} \\
& -( \pm) \Phi_{0} \frac{L_{1}}{L_{\Sigma}} I>0 .
\end{aligned}
$$

によって与えられる。これらの不等式ついて図示 するとFig.4のようになる。

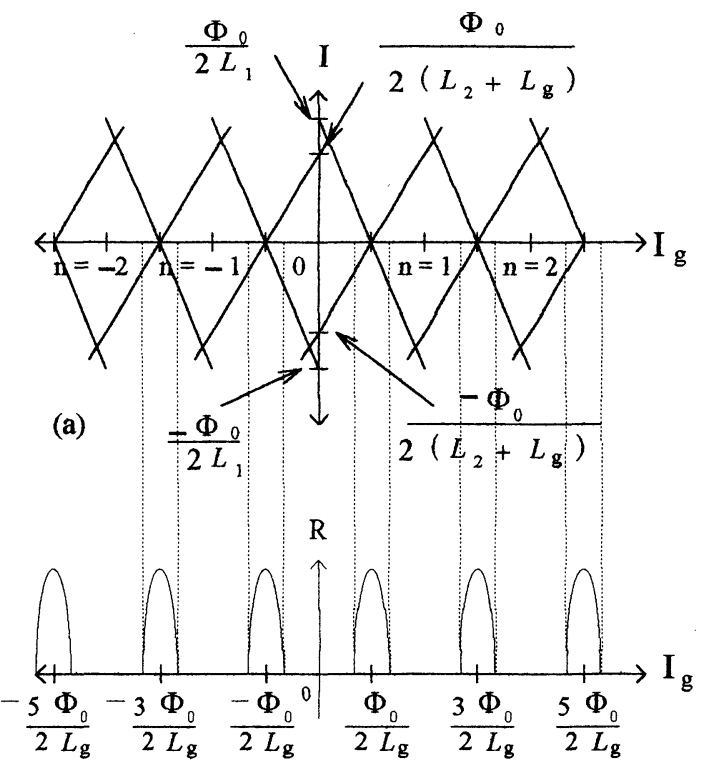

(b)

FIG.4. (a) Current as a function of $I_{g}$

(b) Resistans as afunctionof $I_{g}$ for quantum magnetic flux transistor

Figure4(a)の菱形の内側の領域では、磁気ブロッケ イドによって接合 1 と接合2の磁束量子のトンネリ ングが同時に禁止されるため、超伝導状態が壊れ ず電気抵抗は0である。この部分から外れると磁 気ブロッケイドは解けて磁束量子のトンネルが起 こるため、接合間に起電力が発生し電気抵抗は0 でなくなる。つまり Fig.4(b)のように電気抵抗は ピークを持つ $I_{g}$ の周期関数として図に示したよう

\section{に振動するであろう。}

\section{CONCLUSION}

本論文に於いて我々は、クーロン・ブロッケイ ドとのアナロジーから位相量子トンネル効果を利
用し、単一磁束量子のトンネルを制御する新しい 方法を提案した。そしてFM-S-FM接合を並列に接 続することによって磁束量子トランジスターを考 案し、その動作特性について理論的に調べた。今 後の課題としては、これらの素子を実際に作成し て、実験的にその動作を確認すること、そして従 来のジョセフソン接合を利用した素子である SQUIDとの性能の比較などが挙げられる。

\section{IV.APPENDIX}

このAPPENDIXでは 2 次元系に於けるCooper対 と渦の間の双対関係について簡単にまとめる。

\section{A.1 粒子表現と位相表現との関係}

Cooper対の位相 $\theta(x)$ とVortexの数密度 $N_{v}(x)$ との間 には

$$
\theta(x) \equiv 2 \pi N_{v}(x),
$$

なる関係 ${ }^{11}$ が成立する。これと双対な関係として Cooper対の数 $N_{c}(x)$ とVortex密度場の位相 $\tilde{\theta}(x)$ は

$$
\tilde{\theta}(x) \equiv 2 \pi N_{c}(x) .
$$

により関係付けられる。

超伝導の場合、秩序場とはCooper対の波動関数 $\Psi(x)$ であり、無秩序場とはVortex密度場 $\tilde{\Psi}(x)$ のこ とである。

$$
\begin{gathered}
\psi(x)=\sqrt{N_{c}(x)} \exp [i \theta(x)], \\
\tilde{\psi}(x)=\sqrt{N_{v}(x)} \exp [i \tilde{\theta}(x)],
\end{gathered}
$$

これらの表示を用いると、誘導起電力 $V$ が生じる 原因はCooper対の位相すべりであると同時に Vortexの流れであると解釈出来る。

電位差 $V \Rightarrow$ Cooper対の位相すべり

$\Rightarrow$ Vortexの流れ

$$
\begin{aligned}
V=\frac{\hbar}{2 e} \frac{d \theta}{d t} & =\Phi_{0} \frac{d N_{v}}{d t}, \\
\Phi_{0} & \equiv \frac{h}{2 \pi} ; \text {; 磁束量子. }
\end{aligned}
$$

同様に超伝導電流 I が生じる原因はCooper対の 流れであると同時にVortex密度場の位相 $\tilde{\theta}(x)$ のす ベりであると解釈される。

超伝導電流 $I \Rightarrow$ Cooper対の流れ

$\Rightarrow$ Vortex密度場の位相 $\tilde{\theta}(x)$ のすべり

$$
I=(2 e) \frac{d N}{d t}=\frac{\hbar}{\Phi_{0}} \frac{d \tilde{\theta}}{d t} .
$$


A.2 Cooper対ハミルトニアン (Josephson接合の

ハミルトニアン)

$H_{C P}=4 E_{c} \sum_{i, j}\left[N_{c}(i)-\frac{q(i)}{2 e}\right]\left(M^{-1}\right)_{i j}\left[N_{c}(j)-\frac{q(j)}{2 e}\right]$

$-E_{J} \sum_{\langle i, j\rangle} \cos \left\{\theta(i)-\theta(j)+\frac{2 \pi}{\Phi_{0}} A_{i j}\right\}$,

$E_{c} \equiv \frac{e^{2}}{2 c}$ (単位クーロンエネルギー)，

$E_{J} \equiv \frac{\hbar I_{c}}{2 e}$ (Josephson 結合エネルギー)，

c ; 接合キャパシタンス, $I_{c}$; 臨界電流,

$$
A_{i j} \equiv \int_{i}^{j} d \mathbf{l} \cdot \mathbf{A}=\Phi_{i}-\Phi_{j},
$$

A; vector potential.

(A.5)

正隻方程式からJosephson方程式を導出すると

$$
\begin{aligned}
\frac{\partial \theta(i)}{\partial t}=\frac{1}{\hbar} \frac{\partial H_{c p}}{\partial N_{c}(i)} & =8 E_{c} \sum_{l}\left(M^{-1}\right)_{i l}\left[N_{c}(l)-\frac{q(l)}{2 e}\right] \\
& =\frac{2 \pi}{\Phi_{0}} V(i), \\
\frac{\partial N_{c}(i)}{\partial t} & =\frac{-1}{\hbar} \frac{\partial H_{c p}}{\partial \theta(i)} \\
& =\frac{E_{J}}{\hbar} \sum_{l} \sin \left\{\theta(l)-\theta(i)+\frac{2 \pi}{\Phi_{0}} A_{l i}\right\} .
\end{aligned}
$$

(A.5)の第一項は接合に帯電された電荷に働く静電 エ祤゙ーを表しているが、(A.2a)、(A.2b)のCooper対 の数 $N_{c}(x)$ と Vortex 密度場の位相 $\tilde{\theta}(x)$ の関係 $\tilde{\theta}(x) \equiv 2 \pi N_{c}(x)$ から系の周期性を仮定し逆ガウス近 似を用いると。

$$
\begin{aligned}
& 4 E_{c} \sum_{i, j}\left[N_{c}(i)-\frac{q(i)}{2 e}\right]\left(M^{-1}\right)_{i j}\left[N_{c}(j)-\frac{q(j)}{2 e}\right] \\
& \approx 2 \frac{E_{c}}{\pi^{2}} \sum_{i, j}\left\{1-\cos \left[\tilde{\theta}(i)-\tilde{\theta}(j)-\frac{2 \pi}{2 e} A_{i j}^{Q}\right]\right\}, \\
& A_{i j}^{Q} \equiv q_{i}-q_{j}=\int_{i}^{j} d \cdot \mathbf{A} \mathbf{A}^{Q}=-A_{j i}^{Q},
\end{aligned}
$$$$
\mathbf{A}^{Q} \text {;charged vector potential }
$$

A.3 Vortexのハミルトニアン（dual Josephson接合 のハミルトニアン)

(A.5)のCooper対のハミルトニアンに双対な vortex のハミルトニアンは以下に示される。 $H_{v}=2 \pi^{2} E_{J} \sum_{i, j}\left[N_{v}(i)-\frac{\Phi(i)}{\Phi_{0}}\right]\left(M^{-1}\right)_{i j}\left[N_{v}(j)-\frac{\Phi(j)}{\Phi_{0}}\right]$

$$
-\frac{2}{\pi^{2}} E_{c} \sum_{\langle i, j\rangle} \cos \left\{\tilde{\theta}(i)-\tilde{\theta}(j)+\frac{2 \pi}{2 e} A^{Q_{i j}}\right\} .
$$

正準方程式から次式のdual Josephson方程式が導出 される。

$$
\begin{aligned}
& \frac{\partial \tilde{\theta}(i)}{\partial t}=\frac{1}{\hbar} \frac{\partial H_{v}}{\partial N_{v}(i)}=4 \pi^{2} E_{J} \sum_{l}\left(M^{-1}\right)_{i l}\left[N_{v}(l)-\frac{\Phi(l)}{\Phi_{0}}\right] \\
& =\frac{\Phi_{0}}{\hbar} I(i), \\
& \begin{aligned}
\frac{\partial N_{v}(i)}{\partial t} & =\frac{-1}{\hbar} \frac{\partial H_{v}}{\partial \tilde{\theta}(i)} \\
& =\frac{2}{\pi^{2} \hbar} E_{c} \sum_{l} \sin \left\{\tilde{\theta}(l)-\tilde{\theta}(i)+\frac{2 \pi}{2 e} A_{l i} Q\right\} . \text { (A.9) }
\end{aligned}
\end{aligned}
$$

また(A.5) との対応から

$$
\begin{aligned}
E_{L} \equiv 2 \pi^{2} E_{J} & =2 \pi^{2} \frac{I_{c}}{2 \pi} \Phi_{0}=\frac{\Phi_{0}^{2}}{2 L_{c}}, \\
L_{c} & \equiv \frac{\hbar}{(2 e) I_{c}} .
\end{aligned}
$$

ここで $L_{c}$ は臨界价ダク夕夕スであり、その接合固有の 值を持っている。

A.4 臨界抵抗 $R_{c}$

$$
\begin{aligned}
R & =\frac{V}{I}=\frac{\left(\frac{h}{2 e}\right) \frac{d N_{v}}{d t}}{(2 e) \frac{d N}{d t}} \\
& =\frac{\Phi_{0}}{2 e}\left(\frac{\dot{N_{v}}}{\dot{N}}\right)=\frac{h}{(2 e)^{2}}\left(\frac{\dot{N}_{v}}{\dot{N}}\right) .
\end{aligned}
$$

I ) $\frac{\dot{N}_{v}}{\dot{N}} \ll 1$ のとき

完全な超伝導体の場合、vortexの散逸はなく $\dot{N}_{v}=\frac{d N_{v}}{d t}=0$ であるため、抵抗 $\mathrm{R}=0$ である。こ れはCooper対の秩序パラメータの位相が時間的に変動 せず静的であることを意味している。

II) $\frac{\dot{N}_{v}}{\dot{N}}>1$ のとき

vortexの散逸 $\frac{d N_{v}}{d t}$ がCooper対の散逸 $\frac{d N}{d t}$ と比較して 著しく多くなる。つまり抵抗 Rが非常に大きくな り、絶縁体としての性質が強くなる。

III) $\frac{\dot{N}_{v}}{\dot{N}}=1$ のとき

この場合vortexの散逸数と $\frac{d N_{v}}{d t}$ とCooper対の散逸 
数 $\frac{d N}{d t}$ が全く等しくなっている。つまりvortex と Cooper対の役割を入れ替えても全くdualである。 このときの Rの值は

$$
R_{c} \equiv \frac{h}{(2 e)^{2}}=\frac{\Phi_{0}}{2 e}
$$

となり臨界抵抗と呼ばれる。このときはvortex と Cooper対が同じ可動性を持っている。ここで Josephson接合のハミルトニアン(A.5) の基本定数 である $E_{c}$ と $E_{J}$ の比の臨界值は

$$
\frac{E_{c}}{E_{J}}=\frac{\pi^{2}}{2}\left(R=R_{c}\right) .
$$

となる。以下に $E_{c}$ と $E_{J}$ の大きさの割合から超伝 導一絶縁体転移を考えてみる。

I ) $E_{J} \gg E_{c}$ のとき $T=T_{v}$

$$
T_{v}=\frac{\pi}{2 \varepsilon_{c} E_{J}} .
$$

にてKosterlitz-Thouless転移が起こる。ここで $\varepsilon_{c}$ は 1 より少し小さい定数である。

このとき渦と反渦の pair は非束縛状態にある。 $T<T_{v}$ で系は超伝導状態となる。

II） $E_{J} \ll E_{c} \quad$ のとき $T=T_{c}$

$$
T_{c}=\frac{1}{\pi \varepsilon_{c} E_{c}} .
$$

にてKosterlitz-Thouless転移が起こる。このとき
Cooper対の電荷 $(2 \mathrm{e})$ と $(-2 \mathrm{e})$ のpairは非束縛状態にあ る。 $T<T_{c}$ で系仕絶縁体状態となる。

III) $E_{c}=E_{J} \frac{\pi^{2}}{2}$ のとき

このとき系は超伝導状態にも絶縁体状態なること が出来ず、磁束量子 $\Phi_{0}$ と電荷 $2 e$ の役割を入れ替 えても殆ど同じ方程式に従う。このことを系は自 己双対にあると言う。

\section{REFERENCES}

${ }^{1}$ H.R.Zeller and I.Giaver, Phys.Rev.,181,789(1969)

${ }^{2}$ M.Ueda, Parity 5,No.10 22-28(1990)

${ }^{3}$ M.Ueda, Parity 8,No.09 48-53(1993)

${ }^{4}$ M.A. Kastner, Rev.Mod.Phys.,64,849(1992)

${ }^{5}$ B.J. van Wees, Phys.Rev.B,44,2264(1991)

${ }^{6}$ M.Sugahara, Jpn.J.Appl.Phys.,24,674(1985)

${ }^{7}$ M.Sugahara and N. Yohikawa, Prog. Theor.

Phys, 78,957(1987)

${ }^{8}$ N.Yohikawa,T.Akeyoshi and M.Sugahara, Jpn.J.Appl.Phys,26,L1701(1987)

${ }^{9}$ T.Van Duzer and C.W.Turner, "Principles of Superconductive Device and Circuits",North Holland,New York(1981)

${ }^{10}$ B.I. Halperin and P.C.Hohenberg, Phys.Rev.

188,898(1969)

${ }^{11}$ S.M.Girvin, M.Wallin, M.C.Cha, M.P.A.Fisher and A.P.Young,Prog.Theor.Phys.Supple.No.107,135(1992) 